\section{Process Optimization and DOE Application in the Synthesis of Rociletinib Intermediate}

\author{
S. Kapić, I. Nekola, F. Jović, " and M. Mihovilović \\ Pliva Croatia LTD, TAPI Croatia, \\ TAPI R\&D, Prilaz baruna Filipovića 25, \\ 10000 Zagreb, Croatia
}

\author{
(a) (1) \\ This work is licensed under a \\ Creative Commons Attribution 4.0 \\ International License \\ doi: 10.15255/CABEQ.2017.1200 \\ Original scientific paper \\ Received: August 22, 2017 \\ Accepted: June 4, 2018
}

Critical step of Rociletinib synthesis, regioselective nucleophilic aromatic substitution of $\mathrm{C}-2$ chlorine at pyrimidine molecule 3 with amine 2, was optimised by implementation of pre-DoE screening and DoE-based algorithms. The synthesis reaction was developed and optimised by following a quality by design (QbD) approach, whereby a control strategy was developed for enhanced level of quality assurance. Optimisation of three main parameters (volume of solvent mixture, solvent ratio, and $\mathrm{NaOAc}$ quantity) resulted with good isomer ratio of over 8:1 with respect to desired C-2 isomer 4 with minimum of di-substituted impurity $\mathbf{6}$. The crude product was, however, contaminated with $\mathrm{Zn}$-based inorganics and had to be recrystallized to achieve acceptable purity and assay. Interaction of process variables and their corresponding effects on the percent conversion of maleic acid were discussed. Consistency of statistical model was verified by analysis of variance (ANOVA). API quality specifications (purity, impurity levels) are described across the modelling of process space, which was defined through quality target specifications (conversion NLT $70 \%$; Product Compound 4 NLT $50 \%$, Impurity 5 NMT $20 \%$, and Impurity 6 NMT 0.5).

Keywords:

organic synthesis, Quality by Design (QbD), statistical DoE

\section{Introduction}

As it is known, 5-fluoromethylpyrimidine derivatives are often used as key raw materials in the development of pharmaceutical products, mainly as various kinase inhibitors. ${ }^{1-3}$

Pyrimidine nucleosides containing a trifluoromethyl group at 5-position are known to have significant biological activity. ${ }^{4}$ Fluorinated nucleosides and their analogues represent the class of organofluorine compounds, which found an extensive application in the 70's in biological chemistry, life-science, and medicine branches. ${ }^{5,6}$ The anti-tumor activity of 5-fluorouracil and 5-trifluoromethyluracil derivatives is also reported. ${ }^{7-9}$

Capecitabine (Xeloda1) is the first FDA-approved oral chemotherapy drug for the treatment of both metastatic breast cancer and colorectal cancer, two of the most frequent solid malignancies worldwide. Capecitabine is now extensively prescribed in clinical oncology. This fluoropyrimidine has been designed as a less toxic and more specific alternative to canonical 5-Fluorouracil (5-FU). ${ }^{10}$

Rociletinib 1 is a novel, oral, targeted covalent (irreversible) mutant-selective inhibitor of the can-

*Corresponding author e-mail: franjo.jovic@pliva.com cer-causing mutant forms of epidermal growth factor receptor (EGFR). It was designed to selectively target both the initial activating EGFR mutations and the dominant acquired T790M resistance mutation. Rociletinib is a new chemical entity that contains 5-trifluoro-2,4-diaminopyrimidine moiety as a critical structure motif (Fig. 1a).

Pyrimidines are known to be attacked by nucleophiles at positions C-2 and C-4 of pyrimidine ring. Many examples for nucleophilic substitution reactions of 2,4-dichloropyrimidine having a variety of substituents at 5-position (e. g. $\mathrm{F}, \mathrm{Cl}, \mathrm{Br}, \mathrm{I}_{2} \mathrm{CH}_{3}$, $\mathrm{CH}_{3} \mathrm{O}, \mathrm{CN}$ ) with amines and alcohols, are known to result preferentially with 4-substituted aminopyrimidines. Interestingly, 5-trifluoro substituted pyrimidines provide almost 1:1 mixture of 2-amino and 4-amino product. The primary factors that influence selectivity of this addition are electronically negative nature of trifluoromethyl group accompanied by steric bulkiness. Trifluromethyl group is blocking the approach of a negatively charged nucleophile to the sterically hindered 4-position. ${ }^{11-14}$ As previously reported, addition of Lewis acids (e. g. $\mathrm{ZnCl}_{2}$ ) improved the regioselectivity in favour of substitution at the 2-postion. ${ }^{11,15-17}$ This reaction is described in several patents and articles, published by different authors. ${ }^{11,18-21}$ The theory is that $\mathrm{Zn}$ complexes with the pyrimidine $N-3$ nitrogen, thus 


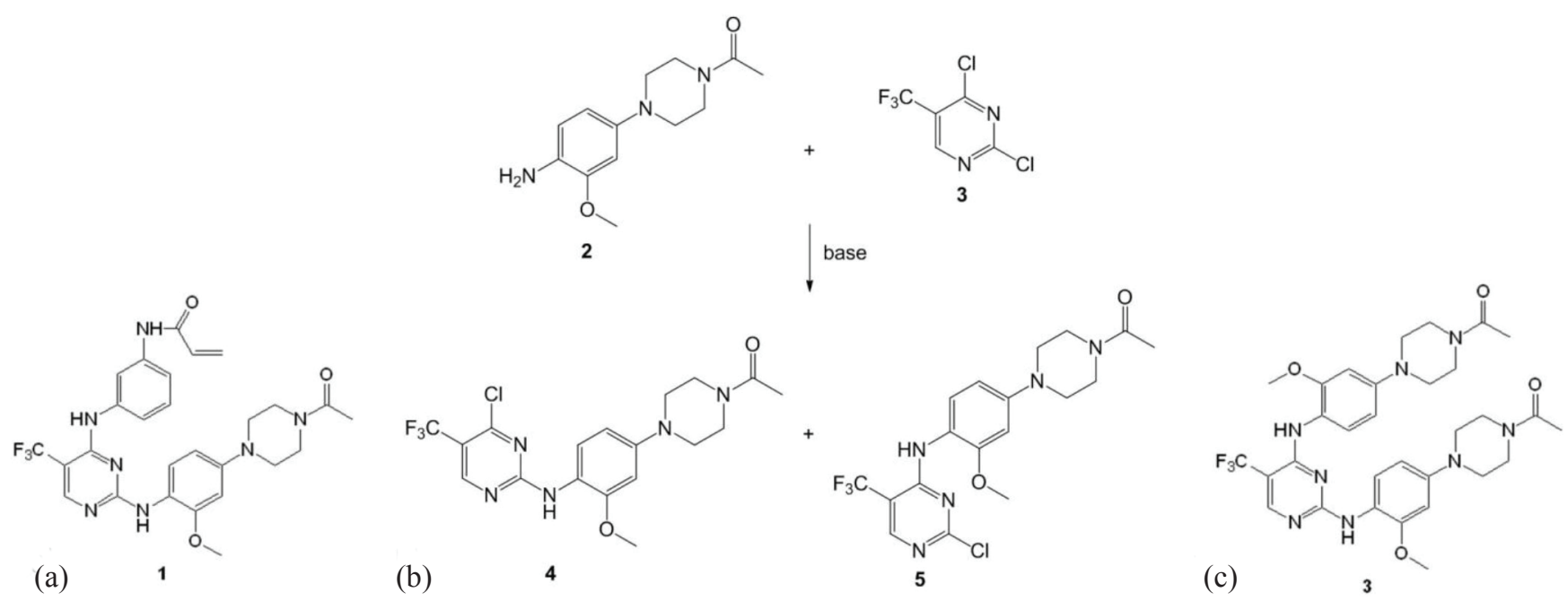

Fig. 1 - Chemical structure of: a) Rociletinib 1, b) regioselective nucleophilic aromatic substitution of C-2 chlorine at pyrimidine molecule 3 with 2 to give an amine 4 as major product and amine 5 as minor product, and c) di-substituted impurity 6

directing chemistry to the less hindered site, to C-2. In this way, with appropriate solvent(s) and base, one could gain high isomer ratio with respect to desired C-2 isomer. Richter et al. from Pfizer presented a good review on this topic. ${ }^{11}$ They tested a series of Lewis acids, and $\mathrm{ZnCl}_{2}$ gave the most selective result. In the mixture of $\mathrm{DCE} / t-\mathrm{BuOH}$ and $\mathrm{Et}_{3} \mathrm{~N}$ as a base $(t-\mathrm{BuOH}$ seemed to be quite important for regioselectivity), 10:1 isomer ratio (in favour of C-2 isomer) was obtained. Although Lewis acid should be present in catalytic amount, $O$-substituted anilines, particularly $o$-methoxy group at anilines (such as in compound 2) are involved in a chelating effect with the Lewis acid, so $\mathrm{ZnCl}_{2}$ should be present even with 2 mol Eqs to obtain good selectivity. Even then, the reaction takes 24 hours to reach completion compared to typical 2-4 hours with anilines while selectivity is usually $5: 1$. Crystallization can be obtained due to moderate selectivity. Thus, firstly, $\mathrm{ZnCl}_{2}$ must form a complex with pyrimidine $\mathbf{3}$ and then with $o$-methoxy substituted aniline 2. Base should be involved to gain satisfactory conversion and regioselectivity (and added last, if possible).

A series of initial experiments have been performed, reaction conditions, solvents and bases have been tested (with or without the presence of $\mathrm{ZnCl}_{2}$ ) to achieve the best isomer ratio: the best initial result was obtained with $\mathrm{K}_{2} \mathrm{CO}_{3}$ as a base, in the presence of $\mathrm{ZnCl}_{2}$ in combination of CPME and $t$ - $\mathrm{BuOH}$ as solvents - ratio $14: 1$ in favour of C-2 isomer was obtained, although the reaction was not completed.

In the development and optimization of this step there were several challenges; one of them was analytics. Following reaction kinetics was difficult because compound $\mathbf{3}$ was unstable in analytical conditions, and isomer compound $\mathbf{5}$ was reacting in the vial with compound $\mathbf{2}$ giving di-substituted compound $\mathbf{6}$ as an impurity (Fig. 1c). Therefore, reaction was usually carried out overnight (min. $20 \mathrm{~h}$ ) and analysed afterwards.

The other major challenge was isolating pure compound 4 from the reaction mixture. Reaction takes place in the mixture of solvents in which compound $\mathbf{2}$ and compound $\mathbf{4}$ are not soluble, so isolation by extraction was not an option. One of the solvents was $t-\mathrm{BuOH}$, which crystallizes at lower temperatures or in vacuo, so filtration in its presence was also not viable - although some attempts of filtration were done after the removal of $t \mathrm{BuOH}$ by distillation. Such filtered crude cake consisted of compound 4, its impurities (mostly 5 and 6 ) and lots of inorganics - preferably $\mathrm{ZnCl}_{2}$ and its hydrolytic products - and it had to be purified in the presence of water in which all the inorganics would be dissolved.

The application of Design of Experiments (DoE) approach to chemical development has been successfully used for several years. ${ }^{22}$ More recently, the practice has been acknowledged by regulatory agencies within the concept of Quality by Design $(\mathrm{QbD}),{ }^{23}$ and it is becoming the base of any well-defined process development strategy within the industry. DoE Study is conducted with the purpose to estimate the effect of Critical Process Parameters (CPPs) and their interactions on relevant Critical Quality Attribute (CQA), and to determine optimum and robust conditions. CPP is a process parameter whose variability has an impact on a critical quality attribute (CQAs) and therefore should be monitored or controlled to ensure the process produces the desired quality. 


\section{Experimental}

\section{Materials}

Amine 2 was produced in our laboratory by internal synthetic method. 5- $\mathrm{CF}_{3}-2,4$-dichloropyrimidine 3 was supplied by Angene International Ltd. as high purity grade. All reagents and solvents were provided by Sigma-Aldrich or Merck, and were of reagent grade.

\section{Analytical methods}

Method for reaction monitoring and chromatographic purity: Instrument. Agilent $1260 / 1290$ or equivalent Column \& Packing: Acquity UPLC BEH C18, 2.1 $\times 100 \mathrm{~mm}, 1.7 \mu \mathrm{m}$ Buffer: $10 \mathrm{mM} \mathrm{KH_{2 }} \mathrm{PO}_{4}$ $\mathrm{pH}=3.5$ ( $\mathrm{pH}$ adjusted with phosphoric acid) Mobile phase: A: Buffer, B: Acetonitrile gradient: 0 . $\min -95 \%$ A, 20. $\min -20 \%$ A, 25. $\min -10 \%$ A, 25.01. $\min -95 \%$ A, 28. $\min -95 \%$ A Run time: 28 min Flow rate: $0.4 \mathrm{~mL} \mathrm{~min}{ }^{-1}$ Injection volume: $1.0 \mu \mathrm{L}$ Detector: 210 (BW $4 \mathrm{~nm}$ ) Column temperature: $40{ }^{\circ} \mathrm{C}$ Autosampler temperature: $10{ }^{\circ} \mathrm{C}$ Diluent: acetonitrile:water 8:2. The process development in PLIVA was supported by Analytical Department, which is in accordance with highest pharmaceutical standards, such as GMP, GLP, etc. All analytical methods were developed and validated.

${ }^{1} \mathrm{H}(500 \mathrm{MHz})$ and ${ }^{13} \mathrm{C}(500 \mathrm{MHz}) \mathrm{NMR}$ spectra were recorded for pyridine solutions at room temperature using Bruker DRX500MHz spectrometer. Peak assignments were aided by ${ }^{1} \mathrm{H}-{ }^{1} \mathrm{H}$ COSY, HMBC and HSQC experiments.

\section{Statistical methods (DoE, QbD)}

Pre-DoE screening of all factors (parameters) on twolevels is conducted to determine CPPs and generally to reduce number of factors. Solvent choice is screened through principal component analysis (PCA). Range of process parameters is important (wide $v s$. narrow region), in process screening the wider range is used, while in late phase the narrower range in which product quality (defined by specifications of CQAs, for example impurities within control range) can be guaranteed. Ranges are also affected by downstream of the process (for example purification factor of isolation to meet specifications, etc.). DoE characterization of reduced number of factors on three levels is conducted to optimize reaction conditions in a systematic way to gain information about linear, interaction, and curvilinear effects. In general, QbD supports product robustness evaluations, product enhancement, as well as product troubleshooting. Pre-DoE as a screening, and $\mathrm{QbD}$ is supported through in depth knowledge of process.

\section{Synthesis}

Final procedure for preparation of 7-(4-(4-((4-chloro-5-(trifluoromethyl)pyrimidin- 2-yl) amino)-3-methoxyphenyl) piperazin-7-yl)ethanone (5)

A one-litre reactor was thermostated to 20-25 ${ }^{\circ} \mathrm{C}$, and $t$-BuOH $(277.5 \mathrm{~mL})$ and $\mathrm{ZnCl}_{2}(37.70 \mathrm{~g}$, $0.277 \mathrm{~mol})$ were charged. MTBE $(277.5 \mathrm{~mL})$ was added and reaction mixture was stirred at $20-25{ }^{\circ} \mathrm{C}$ for 1 hour (until colourless solution was obtained). Compound 3 (19.57 mL, $0.145 \mathrm{~mol}$ ) was added and mixture was stirred at $20-25{ }^{\circ} \mathrm{C}$ for 1 hour to allow compound 3 to form a complex with zinc. Powdered NaOAc (11.34 g, $0.138 \mathrm{~mol})$ was added and reaction mixture was stirred for one more hour at 20-25 ${ }^{\circ} \mathrm{C}$. Finally, compound 2 (34.47 g, 0.138 mol) was added and reaction mixture (yellow suspension) was stirred at $20-25^{\circ} \mathrm{C}$ for 20 hours. Upon cooling to $0{ }^{\circ} \mathrm{C}$, water $(300 \mathrm{~mL})$ was slowly added dropwise to maintain the temperature at $0-5{ }^{\circ} \mathrm{C}$ (thus preventing hydrolysis of pyrimidine chlorine). After all water was added, MTBE and $t$-BuOH were distilled off at diminished pressure (bath temperature max. $\left.45{ }^{\circ} \mathrm{C}\right)$ and acetonitrile $(300 \mathrm{~mL})$ was added into the remaining suspension. The yellow suspension obtained had a $\mathrm{pH}$ value of 3.5 and it was adjusted to 5 with $25 \%$ ammonium hydroxide solution. Reaction mixture was warmed up to $70{ }^{\circ} \mathrm{C}$ when it dissolved. It was slowly cooled to $0{ }^{\circ} \mathrm{C}$ to initiate crystallization (seeding optional). The resulting suspension was stirred for 18 hours at $0{ }^{\circ} \mathrm{C}$, filtered off and the solid was washed with a cold mixture of acetonitrile/water 1:1 cold mixture $(2 \times 120 \mathrm{~mL})$ and dried at $65{ }^{\circ} \mathrm{C} / 150 \mathrm{mbar} / 16 \mathrm{~h}$ yielding $51.33 \mathrm{~g}(86 \%)$ of crude compound $\mathbf{5}$ (purity by UPLC: 95.13 area \%, assay: $64.6 \%$ ). Crude compound 5 was purified by recrystallization as follows: 5 (45 g, $0.105 \mathrm{~mol})$ was suspended in $450 \mathrm{~mL}$ $\mathrm{ACN} /$ water 1:1 mixture and warmed up to reflux temperature while stirring. Hot mixture (thin suspension) was filtered to remove traces of inorganics and the filtrate was warmed up again to $75^{\circ} \mathrm{C}$. Obtained solution was stirred at $75^{\circ} \mathrm{C}$ for 20 minutes and cooled to $45-50{ }^{\circ} \mathrm{C}$ to initiate crystallization. It was stirred at $45-50{ }^{\circ} \mathrm{C}$ for 1 hour, then cooled to $20-25{ }^{\circ} \mathrm{C}$ and stirred overnight, cooled to $0{ }^{\circ} \mathrm{C}$, stirred for 2 more hours and filtered off. Solid was washed with $45 \mathrm{~mL} \mathrm{ACN/water} \mathrm{1:1} \mathrm{cold} \mathrm{mixture}$ and dried at $65{ }^{\circ} \mathrm{C} / 150 \mathrm{mbar} / 16 \mathrm{~h}$ to yield $29.25 \mathrm{~g}$ $(65 \%)$ of crystalline compound 5 (purity by UPLC: 99.65 area \%, assay: $100.2 \%$ ).

\section{Results and discussion}

\section{Pre-DoE screening}

Screening of Lewis acids and content of $\mathrm{ZnCl}_{2}$

Solubility of $\mathrm{Zn}$ compounds depends on the temperature and $\mathrm{pH}$ of the water in question. For 
example, at $\mathrm{pH}<5, \mathrm{ZnCl}_{2}$ is stable. At neutral $\mathrm{pH}$, $\mathrm{Zn}^{2+}$ in water is insoluble because it converts to $\mathrm{Zn}(\mathrm{OH})_{2}$. Solubility increases with increasing acidity. Above $\mathrm{pH} 11$, solubility also increases. Zinc dissolves in water as $\mathrm{ZnOH}^{+}(\mathrm{aq})$ or $\mathrm{Zn}^{2+}(\mathrm{aq})$. Examples of solubility of zinc compounds are: $\mathrm{ZnCl}_{2}$ $4320 \mathrm{~g} \mathrm{~L}^{-1}$ and $\mathrm{ZnO}$ or $\mathrm{ZnSO}_{4} \cdot 7 \mathrm{H}_{2} \mathrm{O} 580 \mathrm{~g} \mathrm{~L}^{-1} \mathrm{etc}^{24,25}$ Unfortunately, anionic $\mathrm{ZnCO}_{3}$ generated from $\mathrm{K}_{2} \mathrm{CO}_{3}$ has a solubility of $0.21 \mathrm{~g} \mathrm{~L}^{-1}$ - and when $\mathrm{K}_{2} \mathrm{CO}_{3}$ was used as a base - depending on its quantity and $\mathrm{pH}$ of the reaction mixture, we often ended up with huge amounts of insoluble $\mathrm{ZnCO}_{3}$ which we could not remove until the final synthesis step. All intermediates and final Rociletinib have very low solubility and are hard to purify from inorganics. Therefore, we had to change the base to one which would (in case of significant change of $\mathrm{pH}$ ) form a water-soluble $\mathrm{Zn}$ salt. Besides $\mathrm{ZnCl}_{2}$, which gave satisfactory results regarding regioselectivity, $\mathrm{LiCl}$ resulted in the opposite selectivity, while $\mathrm{MgBr}_{2}$ did not form a complex with compound $\mathbf{3}$ at all.

As mentioned previously, although Lewis acid should be present in catalytic amount, $o$-methoxy group at compound $\mathbf{2}$ is also involved in a chelating effect with the Lewis acid, so $\mathrm{ZnCl}_{2}$ should be present with 2 mol Eqs to obtain good selectivity. For confirmation, reactions with no $\mathrm{ZnCl}_{2}$ added resulted in low selectivity, even in benefit to C-4 isomer (in acidic conditions, main product is di-substituted pyrimidine 6), and $1.2 \mathrm{~mol} \mathrm{Eq}$ of $\mathrm{ZnCl}_{2}$ was still not enough to gain a good selectivity.

\section{Screening of solvents}

Initial screening of solvents gave different results (Table 1). The main goal was to achieve good conversion, acceptable isomer ratio of C-4 and C-2 isomers and minimizing impurities as well. In the attempt to find the right reaction, solvent principal vector method was applied. A principal component analysis (PCA) is a way to picture the structure of the data as completely as possible by using as few variables as possible, and for that purpose statistical software is used (JMP 12.0). More than 120 different solvents and their combinations were searched according to their physical characteristics, i.e. melting points, boiling points, dielectric constants, refractive indexes, empirical polarity parameters, densities, lipophilicities and solubilities in water. The eigenvalues represent a partition of the total variation in the multivariate sample. Most important parameters were related with polarity and lipophilicity (with eigenvalues of 3.11 and 2.85 which represents $66.25 \%$ of cumulative percentage of the behaviour explained for the eigenvectors). Non-polarity and non-lipophilicity of solvent was desired.

Also, pseudo components for mixtures (MT$\mathrm{BE} / t-\mathrm{BuOH}=1 / 1)$ based on molar ratio were used.
PCA statistical analysis was performed and all ascending candidates were suggested. The main problems with group of candidates were: their reactivity (amines such as morpholine, TEA), high melting point (dioxane), low boiling point (diethylether), and safety (diisopropylether, benzene). Table 1 presents final results of statistical analysis of solvents and combinations of solvents which would give the best C-4:C-2 isomer ratio. Following the results shown above, an extended experimental research was applied to find the right solvent or combination of solvents. Selection of results obtained using different solvents and their mixtures in various volume ratios are presented in Table 2 . The best obtained results were in 1/1 mixtures of CPME (cyclopentylmethyl ether) $/ t-\mathrm{BuOH}$ and $\mathrm{MTBE} / t-\mathrm{BuOH}$. The final choice was $\mathrm{MTBE} / t-\mathrm{BuOH}$ due to the lower boiling point of MTBE (easy to remove if/ when needed) and its lower price. Although a huge number of experiments have been performed using $\mathrm{CPME} / t-\mathrm{BuOH}$ in various ratios and volumes, from this point, mainly experiments with $\mathrm{MTBE} / t-\mathrm{BuOH}$ will be discussed.

Table 1 -Results of different solvents used for principal component analysis (PCA) by JMP

\begin{tabular}{|c|c|}
\hline Solvent & $\begin{array}{l}\text { Predicted C-4:C-2 } \\
\quad \text { isomer ratio }\end{array}$ \\
\hline $\mathrm{CPME} / t-\mathrm{BuOH}$ 1:1 & 10 \\
\hline $\mathrm{MTBE} / t-\mathrm{BuOH} 1: 1$ & 10 \\
\hline $\mathrm{MeOAc}$ & 7 \\
\hline 2-MeTHF & 6 \\
\hline$t-\mathrm{BuOH}$ & 4.5 \\
\hline dimethoxyethane & 5 \\
\hline acetone & 3.8 \\
\hline ethylacetate & 3.4 \\
\hline HMP & 3 \\
\hline diacetone alcohol & 2.5 \\
\hline THF & 2.4 \\
\hline 2-propanol & 2.5 \\
\hline 2-butanol & 2 \\
\hline acetonitrile & 1.3 \\
\hline dichloromethane & 1 \\
\hline ethanol, absolute & 1 \\
\hline$i$-BuOAc & 1 \\
\hline toluene & 0.71 \\
\hline DMA & 0.67 \\
\hline $\mathrm{MeOH}$ & 0.63 \\
\hline NMP & 0.40 \\
\hline MTBE & 0.40 \\
\hline
\end{tabular}


Table 2 - Experimental pre-DoE screening of candidate solvents

\begin{tabular}{|c|c|c|c|c|}
\hline Entry & Solvent $\left(\mathrm{V} \mathrm{m}^{-1}\right)$ & Base (mol Eq) & $\begin{array}{l}\text { Conversion after } 20 \mathrm{~h} \\
\text { (UPLC, area \%) }\end{array}$ & $\begin{array}{c}\text { Isomer ratio } \\
4: 5: 6\end{array}$ \\
\hline 1 & THF, $40 \mathrm{~V}$ & $\mathrm{Et}_{3} \mathrm{~N} 1.20$ & 89.74 & $47.51: 38.04:$ hidden \\
\hline 2 & DMA, $50 \mathrm{~V}$ & NMM 1.10 & 94.67 & $30.37: 52.46: 1.84$ \\
\hline 3 & $\mathrm{ACN}, 50 \mathrm{~V}$ & $\mathrm{~K}_{2} \mathrm{CO}_{3} 1.10$ & 70.65 & $41.37: 21.98: 0.38$ \\
\hline 4 & DCM, $50 \mathrm{~V}$ & $\mathrm{~K}_{2} \mathrm{CO}_{3} 1.10$ & 83.37 & $64.13: 5.07: 0.98$ \\
\hline 5 & 2-PrOH, $50 \mathrm{~V}$ & $\mathrm{~K}_{2} \mathrm{CO}_{3} 1.10$ & 94.85 & $63.94: 19.34: 1.38$ \\
\hline 6 & CPME, $50 \mathrm{~V}$ & $\mathrm{Et}_{3} \mathrm{~N} 1.10$ & 92.23 & $63.50: 25.86$ : hidden \\
\hline 7 & MTBE, $20 \mathrm{~V}$ & $\mathrm{~K}_{2} \mathrm{CO}_{3} 1.10$ & 52.17 & $39.09: 2.21: 0.53$ \\
\hline 8 & $t-\mathrm{BuOH}, 20 \mathrm{~V}$ & $\mathrm{~K}_{2} \mathrm{CO}_{3} 1.10$ & 64.85 & $38.85: 5.62: 5.58$ \\
\hline 9 & $\mathrm{DME} / t-\mathrm{BuOH}$ 1:1.25 V & $\mathrm{K}_{2} \mathrm{CO}_{3} 1.10$ & 97.03 & $70.41: 21.89: 2.77$ \\
\hline 10 & MTBE/EtOH 1:1.20 V & $\mathrm{K}_{2} \mathrm{CO}_{3} 1.10$ & 75.00 & $41.08: 14.75: 1.33$ \\
\hline 11 & MTBE/2-PrOH 1:1.20 V & $\mathrm{K}_{2} \mathrm{CO}_{3} 1.10$ & 59.59 & $42.32: 8.20: 1.13$ \\
\hline 12 & $\mathrm{MTBE} / t-\mathrm{BuOH}$ 1:1.20 V & $\mathrm{K}_{2} \mathrm{CO}_{3} 1.10$ & 97.36 & $73.58: 5.10: 15.48$ \\
\hline 13 & $\mathrm{CPME} / t-\mathrm{BuOH} 1: 1.15 \mathrm{~V}$ & $\mathrm{~K}_{2} \mathrm{CO}_{3} 1.10$ & 95.55 & $74.78: 6.46: 4.32$ \\
\hline
\end{tabular}

Table 3 - Experimental pre-DoE screening of bases (solvent $\mathrm{CPME} / \mathrm{t}-\mathrm{BuOH}, 50 \mathrm{~V} \mathrm{~m}^{-1}, \mathrm{ZnCl}_{2} 2.20 \mathrm{~mol} \mathrm{Eq}$ )

\begin{tabular}{|c|c|c|c|}
\hline Entry & Base (mol Eq) & $\begin{array}{c}\text { Conversion } \\
\text { after } 20 \mathrm{~h} \\
(\mathrm{UPLC}, \text { area \%) }\end{array}$ & $\begin{array}{c}\text { Isomer ratio } \\
4: 5: 6\end{array}$ \\
\hline 1 & $\mathrm{~K}_{2} \mathrm{CO}_{3} 1.10$ & 86.52 & $58.02: 4.10: 0.83$ \\
\hline 2 & $\mathrm{Et}_{3} \mathrm{~N} 1.10$ & 99.24 & $46.26: 40.84: 5.48$ \\
\hline 3 & DIPEA 1.10 & 86.07 & $69.74: 7.02: 2.29$ \\
\hline 4 & NMM 1.10 & 41.73 & $8.51: 4.62: 0.22$ \\
\hline 5 & $\mathrm{NaH} 1.10$ & 74.35 & $48.17: 7.38: 0.71$ \\
\hline 6 & $t$-BuOK 1.10 & 88.74 & $58.44: 7.17: 1.24$ \\
\hline 7 & $\mathrm{~K}_{3} \mathrm{PO}_{4} 1.10$ & 90.53 & $60.09: 18.48: 8.98$ \\
\hline 8 & $\mathrm{KOH} 1.10$ & 85.66 & $61.69: 2.79: 10.09$ \\
\hline 9 & $\mathrm{NaOAc} 1.10$ & 98.17 & $82.71: 7.96: 1.79$ \\
\hline 10 & KOAc 1.05 & 81.41 & $63.61: 7.37: 2.34$ \\
\hline
\end{tabular}

\section{Screening of bases}

In Table 3, only results from $\mathrm{CPME} / t-\mathrm{BuOH}$ $1 / 1$ and $\mathrm{MTBE} / t-\mathrm{BuOH} 1 / 1$ mixtures are shown. The best choice of base regarding regioselectivity was the use of powdered $\mathrm{K}_{2} \mathrm{CO}_{3}$. Isomer ratio with respect to C-2 isomer was 14:1 although conversion was rather slow and reaction mixture had to be warmed up to $50{ }^{\circ} \mathrm{C}$ to achieve $>90 \%$ conversion. The second choice was $t$-BuOK, but it generated degradation impurities. All other bases gave lower isomer ratio (Table 3). Since the exclusion of $\mathrm{K}_{2} \mathrm{CO}_{3}$ due to generation of insoluble $\mathrm{ZnCO}_{3}$, the focus became finding another viable base, which would generate soluble salts, such as $\mathrm{NaOAc}$. Conversion is $95 \%$ if reaction is carried out with $\mathrm{NaOAc}(1.05$ $\mathrm{mol} \mathrm{Eq})$, in MTBE/t-BuOH $1 / 1(16-20 \mathrm{~V})$, at $25{ }^{\circ} \mathrm{C}$ for 20 hours. Besides, temperature increase results information of di-substituted impurity $\mathbf{6}$, which is generated in the reaction between isomer $\mathbf{5}$ and amine $\mathbf{2}$ rather than between compound $\mathbf{4}$ and amine 2 .

\section{Design of Experiments}

From the pre-DoE experiments, it was concluded that three main parameters (volumes and ratios of $\mathrm{MTBE} / \mathrm{t}-\mathrm{BuOH}$ and mol Eqs of $\mathrm{NaOAc}$ ) affect the overall product quality. The final screening design (JMP 12.0.) was chosen for factor screening. Table 4 shows the ranges of process parameters in main DoE characterization of three process parameters. The combination of continuous two-level categorical factors with central point replications was used to describe active two-factor interactions which exhibit strong curvature.

\section{Volumes and ratio of $\mathrm{MTBE} / \mathrm{t}-\mathrm{BuOH}$}

Table 4 presents the results obtained using different volumes and ratios of $\mathrm{MTBE} / t-\mathrm{BuOH}$ mixture. All experiments were done on $20 \mathrm{~g}$ batches using $2.00 \mathrm{~mol} \mathrm{Eq} \mathrm{ZnCl}_{2}$

\section{Content of NaOAc and order of addition}

Content of $\mathrm{NaOAc}$ varied from 1.00 to 1.50 mol Eq which was part of JMP12 design of experiments. Change in $\mathrm{NaOAc}$ content in the reaction mixture can be seen in Table 4 . 
Table 4 -Final DoE with critical 3 parameters (Custom Design with minimal number of experiments)

\begin{tabular}{c|c|c|c|c|c|}
\hline Entry & MTBE/t-BuOH $\left(\mathrm{V} \mathrm{m}^{-1}\right)$ & $\mathrm{MTBE} / t$-BuOH ratio & $\begin{array}{c}\mathrm{NaOAc} \\
(\mathrm{mol} \mathrm{Eq})\end{array}$ & $\begin{array}{c}\text { Conversion after } 20 \mathrm{~h} \\
(\text { UPLC, area } \%)\end{array}$ & $\begin{array}{c}\text { Isomer ratio } \\
4: 5: 6\end{array}$ \\
\hline 1 & 10 & $1: 1$ & 1.50 & 96.14 & $70.00: 9.83: 1.54$ \\
2 & 10 & $5: 1$ & 1.00 & 89.92 & $28.22: 25.59: 0.28$ \\
3 & 18.5 & $1: 1$ & 1.05 & 94.34 & $75.73: 9.02: 0.61$ \\
4 & 20 & $1: 1$ & 1.05 & 89.61 & $66.25: 10.57: 0.28$ \\
5 & 20 & $3: 1$ & 1.25 & 71.19 & $46.30: 25.70: 0.19$ \\
6 & 30 & $1: 1$ & 1.00 & 89.89 & $69.93: 7.62: 0.61$ \\
7 & 30 & $5: 1$ & 1.50 & 25.00 & $13.91: 4.13: 0.00$ \\
8 & 20 & $1: 1$ & 0.00 & 46.56 & $30.41: 2.92: 0.82$ \\
9 & 18.5 & $1: 1$ & 1.05 & 95.53 & $76.29: 8.28: 1.89$ \\
10 & 18.5 & $1: 1$ & 1.05 & 95.38 & $77.17: 8.52: 2.33$ \\
\hline
\end{tabular}

The main conclusion is that excess $\mathrm{NaOAc}$ has no significant impact on the reaction profile, although hydrolytic impurities may increase. Conversely, the lack of base results in low conversion. Thus, $1 \mathrm{~mol} \mathrm{Eq}$ of NaOAc is enough to complete the reaction, which is also confirmed by design of experiments (Fig. 2). NaOAc also has to be used in powdered form to enable the highest possible conversion. Different approaches regarding order of addition of reagents and starting compounds have also been tested. Anion generation at compound 2 followed by addition of previously prepared compound $\mathbf{3} / \mathrm{ZnCl}_{2}$ complex is not an option, since low isomer ratio is obtained in combination with slower con-
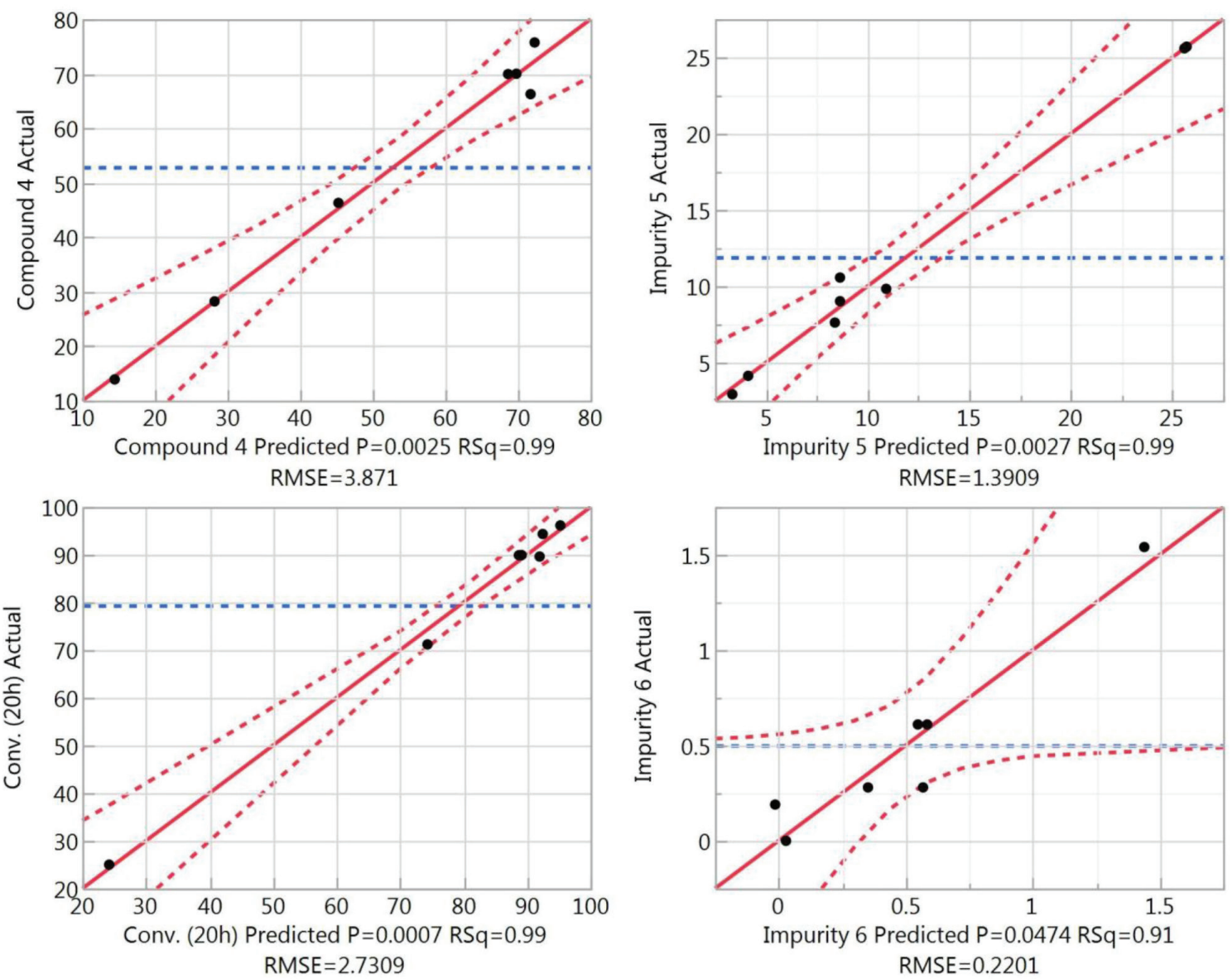

Fig. 2 - Actual vs. predicted plot with summary of fit (RSq, $R^{2}$ and Root Mean Square Error, RMSE) 
version. In case when $\mathrm{NaOAc}$ was added $1 \mathrm{~h}$ after compound 2, isomer ratio was lower (cca 6:1). The best isomer ratio was obtained when compound 2 was added 1 hour after addition of $\mathrm{NaOAc}$ to the complex; isomer compound 5 remained $<2 \%$ and di-substituted compound 6 was cca $5 \%$. However, the material was heterogeneous, impure, and had to be recrystallized. Recrystallization was carried out in $\mathrm{ACN} /$ water $1 / 1(20 \mathrm{~V})$ in average $64 \%$ yield giving overall yield of cca $54 \%$. The optimization of three parameters: volume of solvent, ratio of solvents, and content of $\mathrm{NaOAc}$ resulted in highest value of desirability - acceptable overall conversion, isomer ratio and content of di-substituted impurity (although isomer ratio was higher using higher volumes (Table 4, Raw 6)). The Standard Least Squares statistical model approach fits a wide spectrum of standard models that include regression, analysis of variance, analysis of covariance, and mixed models, as well as the models typically used (a)

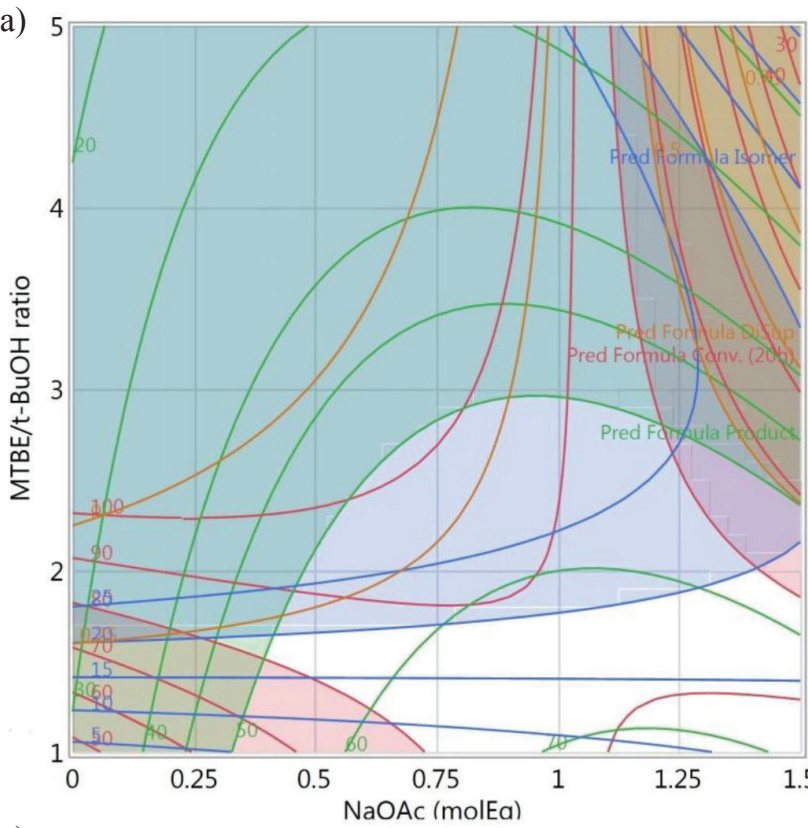

(c)

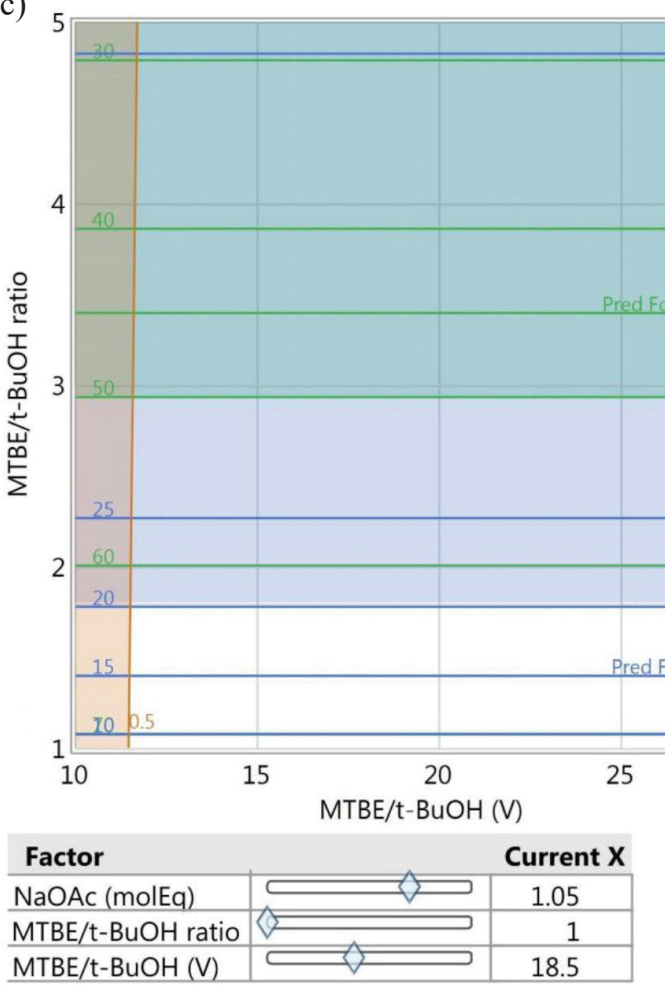

(b)

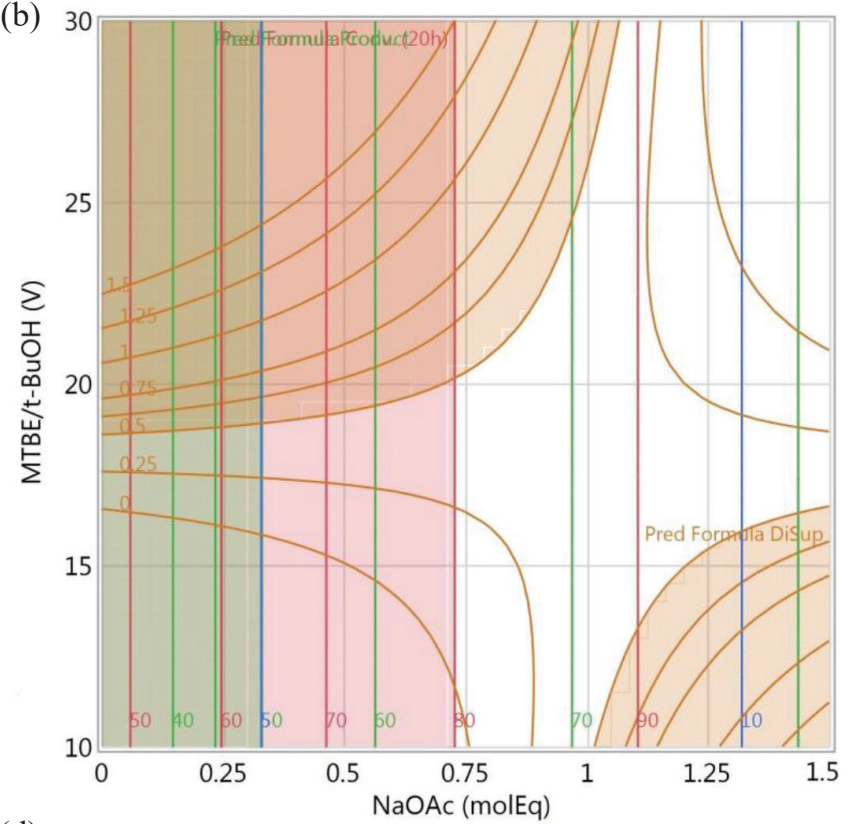

(d)

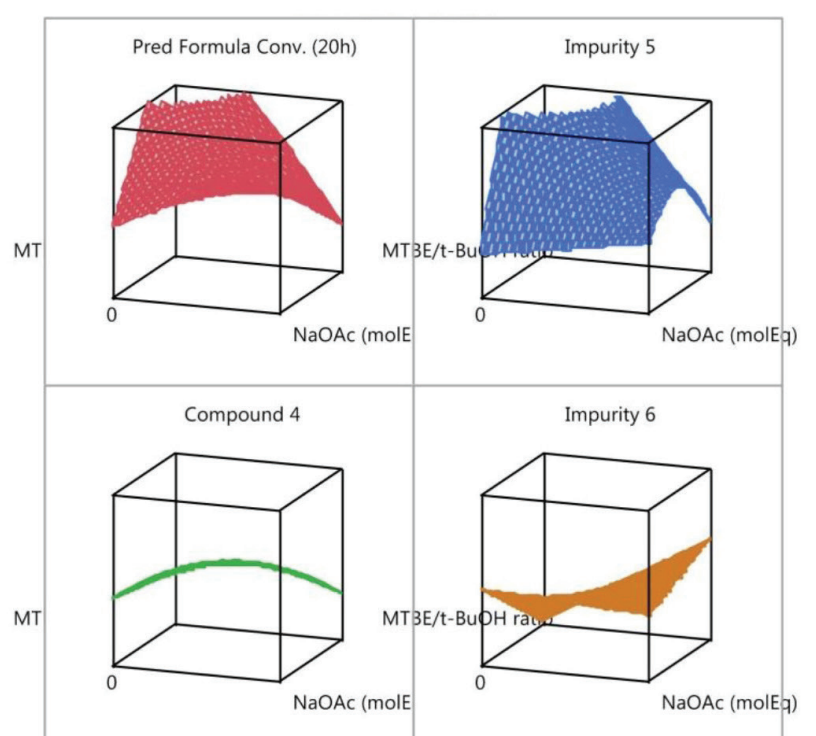

Fig. 3 - Prediction profiler contour plot: a) RSA for mixture of MTBE/t-BuOH and mol Eq of NaOAc, b) volumes and mol Eq of $\mathrm{NaOAc}, \mathrm{c}$ ) mixture of MTBE/t-BuOH and mol Eq of $\mathrm{NaOAc}$, and d) surface profiler 
to analyse designed experiments. In this paper, models are associated with experimental design and involve interaction and quadratic terms. To understand how each variable fit predicted the response, basic statistic is presented in Fig. $2 . R^{2}$ in all responses is $>0.97$ (except in the case of Impurity 6 in which it is $>0.91)$.

In commercial process development, it is important to describe process parameter space in as little time as possible. For that purpose, custom design is used because of its flexibility. Process parameter investigation is made where the parameters were varied - main effects plus their interaction with one central point (default 12 experiments), but minimal number of experiments (Table $4-8$ experiments) was used. Statistical power on individual parameters is between $0.4-0.6$, which is significantly lower than 0.8 which is recommended for statistical analysis. Since the minimal number experiments are used there is some confounding between interactions of parameters. Replications (Table 4, Row 9, on 20-g scale batch, and Table 4, Row 10 , on $35-$ g scale batch) were conducted to validate process optimal conditions and show reproducibility of methods used in this paper.

Analytic results are supported by compelling dynamic visualization tools, such as $2 \mathrm{D}$ contour plots profilers. These visual displays stimulate, complement, and support your understanding of the model. They enable optimisation of several responses simultaneously, and investigation of the effect of noise (Fig. 3). Prediction profiler with maximum desirability set for a Response Surface Analysis, RSA shows the result of the most desirable settings. Finding maximum desirability is an iterative process comprised of four different responses, two to maximize, Conversion and Product - Compound 4 and two to minimize, impurity $\mathbf{4}$ and $\mathbf{5}$, and three factors (critical process parameters). Optimal reaction conditions calculated in JMP12 were 18.5 volumes of $1 / 1$ mixture of $\mathrm{MTBE} / \mathrm{t}-\mathrm{BuOH}$ and 1.05 mol Eq of NaOAc. Fig. 3 shows the area (white surface) where optimum can be achieved: $>80 \%$ conversion, $>50 \%$ of product, Compound $4,<12 \%$ of C-4 isomer, impurity 5 and $<1 \%$ of di-substituted impurity 6. The contour profiler is useful for viewing response surfaces graphically, especially when there are multiple responses as a part of QbD initiative. Model predictions were verified via results obtained in the laboratory by replications of optimal conditions, and the experiments showed good agreement with results obtained by statistical model.

In order to interpret the interaction of different process variables and their corresponding effect, contour plots were drawn (Fig. 3). The clear peaks of contour in Figs. 3a, 3b, 3c indicate that the optimum operating conditions are exactly within the design boundary (conversion NLT $70 \%$; Product Compound 4 NLT $50 \%$, Impurity 5 NMT $20 \%$, and Impurity $\mathbf{6}$ NMT 0.5 ). The combined effect of two independent variables on the response is well illustrated by two-dimensional response surface by maintaining remaining variable at fixed level.

\section{Conclusions}

- Pre-DoE screening of solvents by principal vector method was applied.

- Principal component analysis-most important parameters for good conversion and good regioselectivity were non-polarity and non-lipophilicity-chosen MTBE and $t$-BuOH combination.

- Screening of bases was performed experimentally and NaOAc was chosen as the most appropriate base regarding conversion, regioselectivity and simplicity of removal during isolation.

- The final design of experiments (JMP 12.0) was performed for process realized experimentally, thus confirming that the best conversion and regioselectivity was achieved by applying MTBE/t$\mathrm{BuOH}$ solvent mixture in 1/1 volume ratio, 16-18 $\mathrm{V} \mathrm{m}^{-1}$ and $1 \mathrm{~mol} \mathrm{Eq}$ of $\mathrm{NaOAc}$. Reaction was carried out by complexation of compound 3 (1.05 mol Eq) with $\mathrm{ZnCl}_{2}$ (2.00 mol Eq), followed by addition of $\mathrm{NaOAc}$, and finally addition of compound $\mathbf{2}$ (1.00 mol Eq) after one hour.

\section{ACKNOWLEDGEMENTS}

The Authors thank Analytics Team for the development of analytical methods, including Tomislav Biljan, for close collaboration on the NMR data.

\section{References}

1. Lee, H. J., Latif, M., Choe, H., Ali, I., Lee, H. K., Yang, E. H., Yun, J. I., Chae, C. H., Jung, J. K., Kim, H. R., Lee, C. O., Park, C. H., Lee, K., ALK inhibitors of bis-ortho-alkoxy-para-piperazinesubstituted-pyrimidines and -triazines for cancer treatment, Arch. Pharm. Res. 37 (2014) 1130 .

doi: https://doi.org/10.1007/s12272-013-0323-z

2. Lücking, U., Jautelat, R., Krüger, M., Brumby, T., Lienau, P., Schäfer, M., Briem, H., Schulze, J., Hillisch, A., Reichel, A., Wengner, A. M., Siemeister, G., The lab oddity prevails: Discovery of pan-CDK inhibitor (R)-S-cyclopropyl-S-(4$\{[4-\{[(1 \mathrm{R}, 2 \mathrm{R})-2-$ hydroxy-1-methylpropyl]oxy $\}-5-($ trifluoromethyl)pyrimidin-2-yl]amino phenyl)sulfoximide (BAY 1000394) for the treatment of cancer, Chem. Med. Chem. 8 (2013) 1067

doi: https://doi.org/10.1002/cmdc.201300096

3. Yang, E. H., Yun, J. I., Latif, M., Lee, H. J., Yun, Ch.-S., Lee, K., Park, C. H., Cho, S. Y, Jung, H. J., Kim, P., Du Ha, $J ., K i m, H$. R., New pyrimidine derivatives possessing ALK inhibitory activities, Bull. Korean Chem. Soc. 34 (2013) 3129. doi: https://doi.org/10.5012/bkcs.2013.34.10.3129 
4. Heidelberger, $C$., Chemical carcinogenesis, chemotherapy: cancer's continuing core challenges - - - G.H.A. Clowes memorial lecture, Cancer Res. 30 (1970) 1549.

5. Cavaliere, A., Probst, K. C., Westwell, A. D., Slusarczyk, M., Fluorinated nucleosides as an important class of anticancer and antiviral agents, Future Med. Chem. 9 (2017) 1809. doi: https://doi.org/10.4155/fmc-2017-0095

6. Périgaud, C., Gosselin, G., Imbach, J. L., Nucleoside analogs as chemotherapeutic agents: A review, Nucleosides Nucleotides 11 (1992) 903. doi: https://doi.org/10.1080/07328319208021748

7. Heidelberger, C., Parsons, D. G., Remy, D. C., Syntheses of 5-trifluoromethyluracil and 5-trifluoromethyl-2'-deoxyuridine, J. Med. Chem. 7 (1964) 1. doi: https://doi.org/10.1021/jm00331a001

8. Dipple, A., Heidelberger, C., Fluorinated pyrimidines. 28. The synthesis of 5-trifluoromethyl-6-azauracil and 5-trifluoromethyl-6-aza-2'-deoxyuridine, J. Med. Chem. 9 (1966) 715 . doi: https://doi.org/10.1021/jm00323a017

9. Cech, D., Wohlfeil, R., Etzold, G., A facile synthesis of 5-(perfluoroalkyl)-pyrimidines, Nucl. Acid. Res. 2 (1975) 2183. doi: https://doi.org/10.1093/nar/2.11.2183

10. Mercier, C., Ciccolini, J., Severe or lethal toxicities upon capecitabine intake: Is DPYD genetic polymorphism the ideal culprit?, Trends Pharmacol. Sci. 28 (2007) 597. doi: https://doi.org/10.1016/j.tips.2007.09.009

11. Richter, D. T., Kath, J. C., Luzzio, M. J., Keene, N., Berliner, M. A., Wessel, M. D., Selective addition of amines to 5-trifluoromethyl-2,4-dichloropyrimidine induced by Lewis acids, Tetrahedron Lett. 54 (2013) 4610. doi: https://doi.org/10.1016/j.tetlet.2013.06.025

12. MacPhee, J. A., Panaye, A., Dubois, J. E., Steric effects. I. A critical examination of the Taft steric parameter - Es. Definition of a revised, broader and homogeneous scale. Extension to highly congested alkyl groups, Tetrahedron 34 (1978) 3553. doi: https://doi.org/10.1016/0040-4020(78)88431-2

13. Charton, M., Steric effects. Esterification and acid-catalyzed hydrolysis of esters, J. Am. Chem. Soc. 97 (1975) 1552. doi: https://doi.org/10.1021/ja00839a047

14. Hirsch, J. A., Table of conformational energies-1967, Top. Stereochem. 1 (1967) 199. doi: https://doi.org/10.1002/9780470147108.ch4

15. Walker, D. P., Zawistoski, M. P., McGlynn, M. A., Li, J. C., Kung, D. W., Bonnette, P. C., Baumann, A., Buckbinder, L., Houser, J. A., Boer, J., Mistry, A., Han, S., Xing, L., Guzman-Perez, A., Sulfoximine-substituted trifluoromethylpyrimidine analogs as inhibitors of proline-rich tyrosine kinase 2 (PYK2) show reduced hERG activity, Bioorg. Med. Chem. Let. 19 (2009) 3253. doi: https://doi.org/10.1016/j.bmcl.2009.04.093
16. Curtin, M. L., Heyman, H. R., Frey, R. R., Marcotte, P. A. Glaser, K. B., Jankowski, J. R., Magoc, T. J., Albert, D. H., Olson, A. M., Reuter, D. R., Bouska, J. J., Montgomery, D. A., Palma, J. P., Donawho, C. K., Stewart, K. D., Tse, C., Michaelides, M. R., Pyrazole diaminopyrimidines as dual inhibitors of KDR and Aurora B kinases, Bioorg. Med. Chem. Lett. 22 (2012) 4750. doi: https://doi.org/10.1016/j.bmcl.2012.05.067

17. Walker, D. P., Bi, F. C., Kalgutkar, A. S., Bauman, J. N., Zhao, S. X., Soglia, J. R., Aspnes, G. E., Kung, D. W. Klug-McLeod, J., Zawistoski, M. P., McGlynn, M. A., Oliver, R., Dunn, M., Li, J. - C., Richter, D. T, Cooper, B. A., Kath, J. C., Hulford, C. A., Autry, C. L., Luzzio, M. J., Ung, E. J., Roberts, W. G., Bonnette, P. C., Buckbinder, L., Mistry, A., Griffor, M. C., Han, S., Guzman-Perez, A., Trifluoromethylpyrimidine-based inhibitors of proline-rich tyrosine kinase 2 (PYK2): Structure-activity relationships and strategies for the elimination of reactive metabolite formation, Bioorg. Med. Chem. Lett. 18 (2008) 6071. doi: https://doi.org/10.1016/j.bmcl.2008.10.030

18. Nadia, H., Deqiang, N., Russell, P., Lixin, Q., Juswinder, S., Zhendong, Z., (Celgene Avilomics Research, Inc.) WO2014124230A2, 14 Aug 2014; C. A. 161 (2014) 361034.

19. Foitzik, R. C., Morrow, B. J., Hemley, C. F., Lunniss, G. E., Camerino, M. A., Ganame, D., Stupple, P. A., Lessene, R., Kersten, W. J. A., Harvey, A. J., Holmes, I., P. (Canser Therapeutics Crc Pty Ltd.) WO2014026243A1, 20 Feb 2014; C. A. 160 (2014) 356376.

20. Kath, J. C., Luzzio, M. J. (Pfizer Inc.) U. S. Pat. Appl. US20050256125A1, 17 Nov 2005; C. A. 143 (2005) 460185.

21. Math, J. C., Richter, D. T., Luzzio, M. J. (Pfizer Inc.) U. S. Pat. Appl. US7122670A1, 12 May 2005; C. A. 142 (2005) 298127.

22. Martinot, T. A., Austad, B. C., Côté, A., Depew, K. M., Genov, D., Grenier, L., Helble, J., Lescarbeau, A., Nair, S., Trudeau, M., White, P., Yu, L.-C., A Design of experiments approach to a robust final deprotection and reactive crystallization of IPI-926, a novel hedgehog pathway inhibitor, Org. Process Res. Dev. 19 (2015) 1693. doi: https://pubs.acs.org/doi/abs/10.1021/acs.oprd.5b00214

23. Metil, D. S., Sonawane, S. P., Pachore, S. S., Mohammad, A., Dahanukar, V. H., McCormack, P. J., Reddy, C. V, Bandichhor, R., Synthesis and optimization of canagliflozin by employing quality by design (QbD) principles, Org. Process Res. Dev. 22 (2018) doi: https://doi.org/10.1021/acs.oprd.7b00281

24. Reddy, K. J., Wang, L., Gloss, S. P., Solubility and mobility of copper, zinc and lead in acidic environments, Plant and Soil 171 (1995) 53. doi: https://doi.org/10.1007/BF00009564

25. http://www.lenntech.com/periodic/water/zinc/zinc-andwater.htm (30. 08. 2017.) 